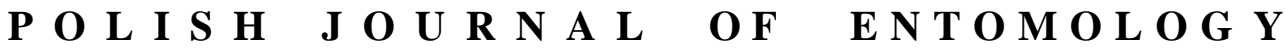

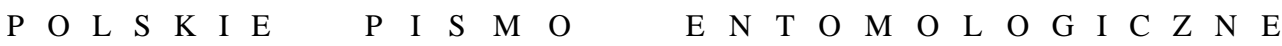

VOL. 86: 99-118

Lublin

30 June 2017

DOI: $10.1515 /$ pjen-2017-0008

\section{Effect of food types on competitive interaction between Aedes aegypti (LINNAEUS, 1762) and Ae. albopictus (SKUSE, 1894) (Diptera, Culicidae): a proximate level appraisal}

\author{
SAMPa BANERJEe ${ }^{1}$, Sushree Mohan ${ }^{1}$, SOUJiTA PramaniK ${ }^{1}$, SOUMYAJIT \\ BANERJEE $^{2}$, GOUTAM K. SAHA ${ }^{1}$, GAUTAM ADITYA ${ }^{1 *}$ \\ ${ }^{1}$ Department of Zoology, University of Calcutta, 35 Ballygunge Circular Road, \\ Kolkata 700019, India \\ ${ }^{2}$ P.G. Department of Zoology, Serampore College, Serampore 712201, India
}

\begin{abstract}
Competitive interactions between coexisting Aedes aegypti and Ae. albopictus have been implied as a crucial factor shaping life history traits and population characteristics. The overlap in resource requirements and similarities in the life history strategies of the two Aedes mosquitoes form a basis for competitive interactions. In the present study, the role of the food quality of the larval habitats in influencing the outcome of competition between Ae. aegypti and Ae. albopictus is evaluated to highlight food quality as a basis for asymmetric competitive outcomes. Instar I larvae of the two mosquitoes were reared using conspecifics or heterospecifics of constant size and equal ratio with four different food types: boiled rice, boiled pulses, a mixture of boiled rice and pulses, and fish food. Competitive interactions were evaluated using age at pupation (AP), pupal weight (PW), dry adult weight (AW) and wing length (WL) with respect to intra- and interspecific competition for the two sexes of each mosquito species. The results show that $A e$. albopictus developed faster but achieved a smaller size compared to Ae. aegypti under interspecific competition conditions, the extent of the difference varying significantly with the food type. Given the variety of food resources available in the small container larval habitats, the results of the study imply that food quality may act differentially with respect to larval development and adult body size, depending on the conspecifics or heterospecifics and on the sex of the species concerned. The dominance of one species over the other may also be a consequence of the resource utilization pattern that varies in the larval habitats.
\end{abstract}

KEY WORDS: Aedes, resource based competition, life history traits, food type.

* Corresponding author: gautamaditya2001@gmail.com 


\section{INTRODUCTION}

The coexistence of the dengue vectors Aedes aegypti (LinNaEus, 1762) and Ae. albopictus (SKUSE, 1894) (Diptera: Culicidae) in different larval habitats has been reported from various geographical locations (O'MEARA et al. 1995, BRAKS et al. 2004, JULIANO et al. 2004, REY et al. 2006, KAMGANG et al. 2010). The similarities in life history strategies and the resources required for larval development result in an overlap of spatial occupancy in available larval habitats by both mosquito species (MERRITT et al. 1992, O'MEARA et al. 1995, WALKER et al. 1996, JULIANO et al. 2002, 2004). Consequently, developing larvae of Ae. aegypti and Ae. albopictus may compete for resources, the outcome of which may vary with the relative abundance of the two species in the larval habitats (AGNEW et al. 2002, ARRIVILlAGA \& BARRERA 2004, BÉDHOMME et al. 2005, LEGROS et al. 2009, REISKIND \& LOUNIBOS 2009, ALTO et al. 2015). In addition to numerical abundance, environmental factors like temperature (LOUNIBOS et al. 2002, KIRBY \& LINDSAY 2009, WESTBROOK et al. 2010, COURET et al. 2014, EWING et al. 2016) and food resources (RENSHAW et al. 1994, ARRIVILLAGA \& BARRERA 2004) influence the outcome of larval development. The outcome of both interspecific and intraspecific competition influences the population dynamics of both these mosquito species, as is evident from different laboratory and field studies (AGNEW et al. 2002, GAVOTTE et al. 2009, GILLES et al. 2011). Competitive effects can be evaluated through variations in life history traits like pupal weight, adult weight and wing length (AGNEW et al. 2002, JULIANO 2009, 2010). The life history traits in mosquitoes are determined by the larval feeding characteristics, which in turn depend on the resources available in their habitats. Resource-based competitive interactions have been studied in different forms, which has led to the concept of context-dependent competition between mosquitoes, especially between Ae. aegypti and Ae. albopictus (JULIANO 2009). Assessment of variations in life history traits is a feasible way of accounting for competitive interactions within and between mosquito species.

Competitive interactions vary with the strains and origin of the mosquitoes and the local conditions that define the population. For instance, both mosquito species are observed in household waste containers that may carry organic residues of diverse origin, particularly as regards food and beverages (VEZZANI \& SCHWEIGMANN 2002). In conditions where resources are abundant, differences in their quality may have consequences for the tempo of larval development, inclusive of the preference for a resource by one or other of the mosquito species. Whereas earlier studies mostly described the effects of resource quantity on competitive interactions, few dealt with the quality of the resources available. Plantbased detritus provides Ae. albopictus with a competitive advantage over Ae. aegypti (JULIANO 1998, BRAKS et al. 2004), which is reduced by the presence of animal carcasses (DAUGHERTY et al. 2000). There is evidence suggesting that animal-based resources favour 
Ae. aegypti (MOORE \& FISHER 1969), whereas plant-based resources favour Ae. albopictus (BARRERA 1996, MURRELl \& JULIANO 2008): consequently, the competitive interaction between the two mosquito species can be described as context-dependent (JULIANO 2009). The diversity of larval habitats and resources present therein supports the hypothesis of context-dependent competitive interactions between the two congeneric mosquito species. In Kolkata, India, the diversity of larval habitats of Aedes MeIGEN, 1818 mosquitoes suggests the presence of a varied type of resources in them, which can influence the outcome of competition in developing larva (BANERJEE et al. 2013b, 2015a). Pupal productivity from the larval habitats of Kolkata indicates that both species occupy them, although the relative density varies considerably (MoHAN et al. 2014). A study was therefore conducted using larval food types as an explanatory factor for the outcome of inter- and intraspecific competition between Ae. aegypti and Ae. albopictus in Kolkata, India. The experimental design employed in the present study would enable an assessment of the resource quality dependent variations in the competitive interactions in the two Aedes mosquitoes. While reduction in larval habitats has been highlighted in the past, the consequences of varying resource quality on larval development and population fitness level have remained unexplored. Body size and various other life history traits are crucial measures for predicting the disease transmission potential of mosquitoes. Thus, an evaluation of life history trait related variations arising out of the competition linked to resource quality variations would help to understand population level variations in Aedes mosquitoes with greater clarity.

\section{MATERIAL AND METHODS}

\section{Laboratory rearing and experimental design}

Laboratory culture was initiated following the collection of the immature stages of the two mosquito species (Ae. aegypti and Ae. albopictus) from different larval habitats in selected sites of urban and suburban Kolkata (BANERJEE et al. 2013a, 2013b, 2015b). Field collected immatures were treated as the P-generation, which were reared to obtain the $\mathrm{F}_{2}$ generation 0 day old $(<6 \mathrm{hr}$ ) instar I larvae (AMBRUSTER \& HUTCHINSON 2002) to initiate the experiment. From the general collection of P-generation immatures, individual pupae were placed in vials and, upon emergence as adult mosquitoes (P-generation), the species were identified and then segregated. The adults (P-generation) of Ae. aegypti and Ae. albopictus were reared separately in wooden cages with the provision of $20 \%$ sucrose solution on the first and third days and blood fed on the second and fourth days post emergence. The rearing procedure for the two mosquitoes complied strictly with the synchronized hatching of eggs, and the emerging instar $I$ larvae $\left(F_{1}\right.$ generation) were 
transferred immediately after hatching to plastic containers $\left(100 \mathrm{ml}\right.$, Tarson ${ }^{\circledR}$ specimen container, India) containing $75 \mathrm{ml}$ of deionised water and tap water (1:1 ratio) and placed inside a wooden mosquito cage. In each container, fish food (Tokyu ${ }^{\circledR}$, Japan) was provided ad libitum and the water was changed daily. The relative humidity was maintained above $80 \%$ by placing a water-filled tub below the wooden mosquito cage. The temperature remained between 25 and $27^{\circ} \mathrm{C}$ under laboratory conditions during the monsoon period (July to September 2013). Following emergence of the $\mathrm{F}_{1}$-generation adults, the mosquitoes were fed with $20 \%$ sucrose solution, and then blood at the end of the third and fifth days post emergence. The mosquito cages were provided with oviposition substrates with either moist tissue paper in a Petri dish or a small specimen container filled with aged tap water. The culture was maintained for the two species Ae. aegypti and Ae. albopictus separately following their initial separation from the F1-generation adults. Monitoring of the containers with eggs was continued to obtain the desired larval stages of both species.

In order to assess the competitive interactions, the $F_{2}$ generation 0 day old $(<6 \mathrm{hr})$ instar I larva were reared under three different species ratios with four different food types being supplied. Maintaining a constant rearing density ( 20 individuals $/ 100 \mathrm{ml}$ water), the number of individual larvae of Ae. aegypti and Ae. albopictus was A) 20:0 (Intraspecific competition between Ae. aegypti), B) 10:10 (Interspecific competition between Ae. aegypti and Ae. albopictus) and C) 0:20 (Intraspecific competition between Ae. albopictus) per container. Four different types of food were provided: fish food (used as a balanced diet), Boiled Rice (rich in carbohydrate), boiled pulses (rich in protein) and both boiled rice and pulses (mixture of carbohydrate and protein) ad libitum. These 12 treatments (4 food types x 3 initial densities) were replicated 3 times, and appropriate monitoring was carried out for the rearing of the larvae under these experimental conditions. The temperature and relative humidity of the laboratory were also maintained at $25 \pm 1{ }^{\circ} \mathrm{C}$ and $50 \pm 2 \%$ respectively.

The containers were monitored daily for pupation. Upon pupation the date of pupation was recorded (AP - Age at Pupation) and individual pupae were weighed (PW - Pupal Weight) to the nearest $0.1 \mathrm{mg}$ using a pan balance $\left(\mathrm{ADAM}^{\circledR}, \mathrm{ADA} 71 / \mathrm{L}\right.$, Adam Equipment, UK). Then, the individual pupae were placed in small glass vials containing $5 \mathrm{ml}$ of doubly distilled water, after which these were covered with fine cloth for eclosion. The vials were numbered serially with regard to the date of pupation and the respective initial density and food treatment. Following eclosion, the water was removed from the vials using a sterile syringe, and the sex (for both intraspecific and interspecific competition) and species (for interspecific competition) of the emerging adults were noted and recorded. After the natural death of the mosquitoes, the adult dry weight (AW - Adult Weight) was recorded to the nearest $0.1 \mathrm{mg}\left(\mathrm{ADAM}^{\circledR}\right.$, ADA 71/L, Adam Equipment, UK). The wings of the individual mosquitoes were removed and their lengths measured to the nearest $0.1 \mathrm{~mm}$ using 
a dissecting stereomicroscope (Olympus ${ }^{\circledR}$ SZX, Olympus Corporation, Tokyo, Japan) fitted with an ocular micrometer $\left(\right.$ Erma $^{\circledR}$, Japan). The experimental design is outlined in Fig. 1.

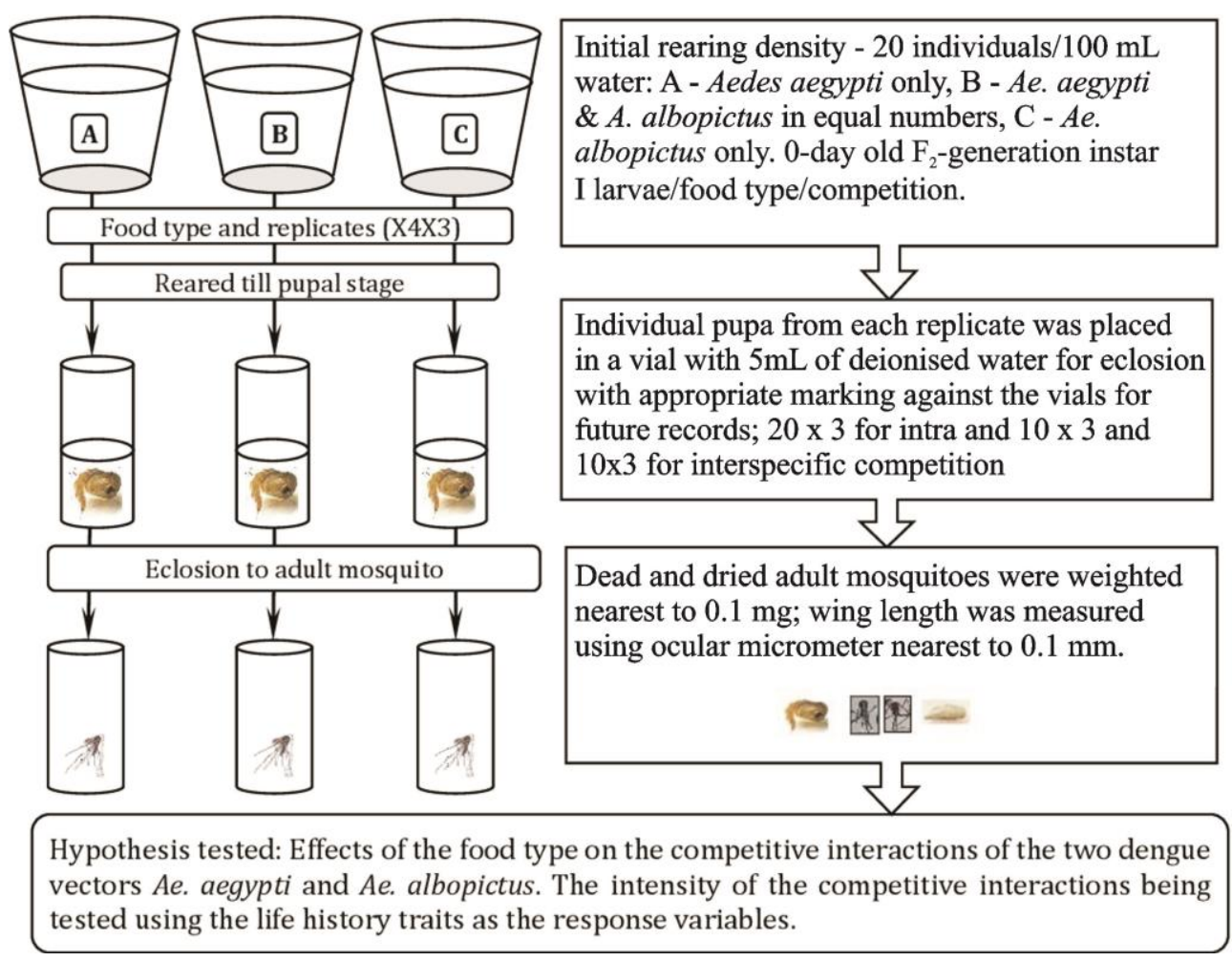

Fig. 1. Outline of the experimental design followed in the study. In all instances $F_{2}$ generation 0-day old $(<6 \mathrm{~h})$ instar I larvae were considered for the experiments.

\section{Statistical analysis}

In order to assess the effects of competition on life history traits (age at pupation - AP, in days; pupal weight - PW, in mg; adult body weight - AW, in mg; wing length - WL, in $\mathrm{mm}$ ), the food types, sexes, and types of competition regarded as explanatory variables and a logistic regression complying with the binomial generalized linear model with logit link was employed to comment on the variations in the life history traits of the two Aedes mosquitoes. In the logistic regression, a particular life history trait (response variable) was assumed to follow a binomial (n, p) distribution with $\mathrm{n}$ replicates (sampling efforts) for each treatment level (the levels of the explanatory variables; Food type -4 , sex -2 and competition -2 ). The linear combination of the explanatory variables was represented by 
the probability parameter p. A weighted binary function with logit link was employed and the parameters were estimated by maximum likelihood using XLSTAT software (ADDINSOFT 2010). The equation is represented as life history trait $(\mathrm{y})=1 /(1+\exp (-$ (a $\left.\left.\left.+b_{1} x_{1}-b_{2} x_{2}-b_{3} x_{3}\right)\right)\right)$, where $x_{1}$ is food type, $x_{2}$ is competition, $x_{3}$ is sex. The Chi square value (Wald's Chi-square) was used to deduce the significance of the estimated parameters of the model.

The analysis was extended with univariate ANOVA using food types, sex and competition type as the explanatory variables against each of the life history traits for each species. Thus, four separate ANOVAs were conducted to deduce the individual and interactive effects of the sources of variations (explanatory variables). The partial $\eta^{2}$ values against each of the sources indicate the extent of the variations explained by a particular factor, either independently or as an interaction (ZAR 1999). The differences in life history traits between the two Aedes species reared using four different food types were assessed following DAUGHERTY et al. (2000) and the data compared using the Kruskal-Wallis test with multiple comparisons. The analysis was further extended using GLM Mixed model ANOVA, taking different food types and sex as explanatory variables and the differences in life history traits between Ae. aegypti and Ae. albopictus as response variables. The statistical analyses were performed following ZAR (1999) using XLSTAT (ADDINSOFT 2010).

\section{RESULTS}

The competitive interactions between Ae. albopictus and Ae. aegypti were evident as a result of rearing density and variation in food type. Life history traits like age at pupation (AP), pupal weight (PW), adult weight (AW) and wing length (WL) varied significantly between the two competitive interactions encountered during the larval stages (Fig. 2). In conspecific conditions, the differences in the life history traits were evident and comparable to the heterospecific conditions. The extent of competitive interactions varied with the food type, although the effects were similar in both species (Fig. 2). Although males emerged as adults faster than females, the females of both species performed better under both conspecific and heterospecific conditions with respect to the remaining traits (PW, AW and WL) (Fig. 2). The results of GLM depicted significant differences in AP, PW, AW and WL for both species as explained by the treatment factors, i.e. food type, density and sex. Wald's chi square values explained the significant contribution of explanatory variables to the response variables (Table 1). 


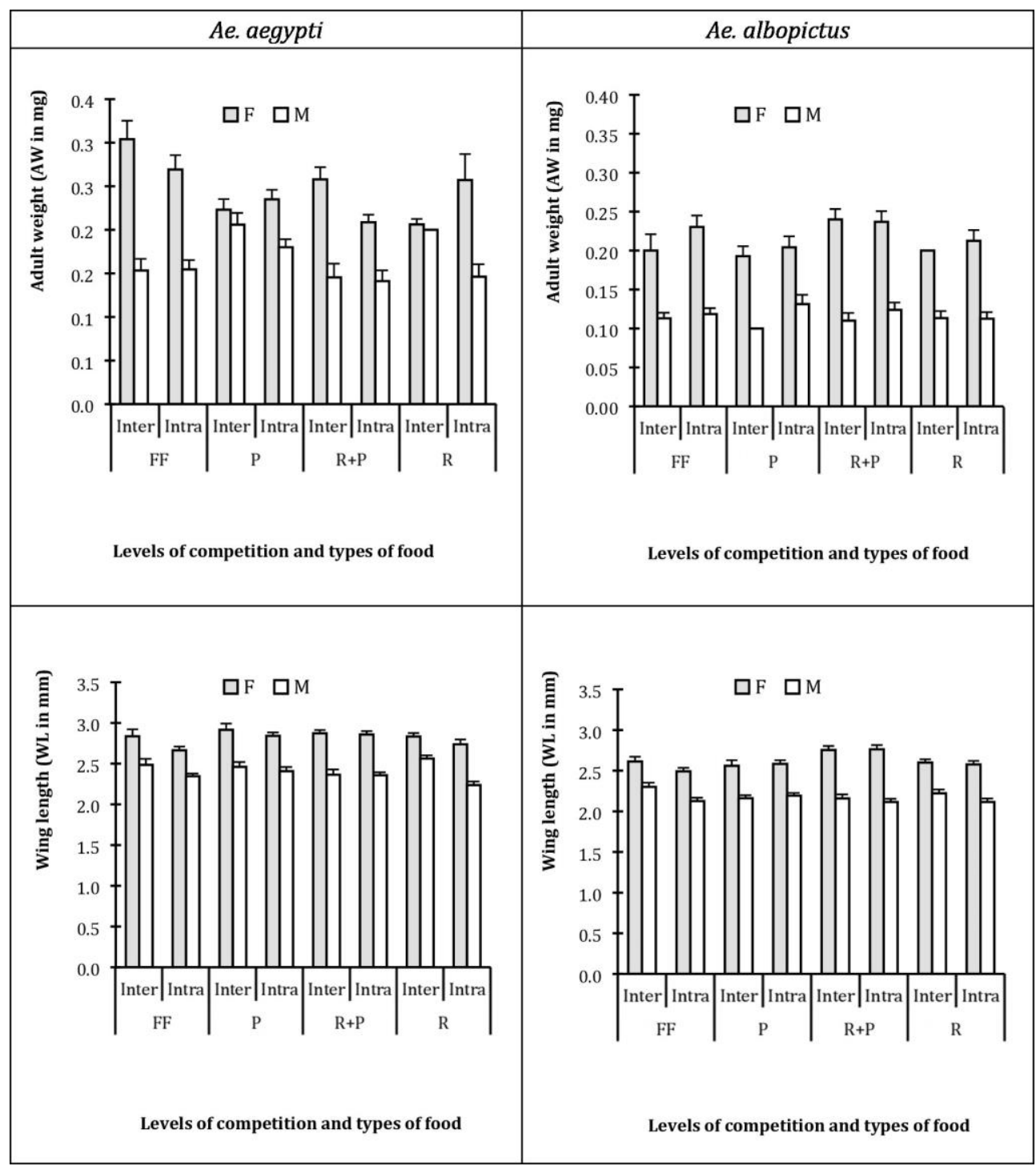

Fig. 2. Life history traits (AP - age at pupation in days; PW - pupal weight in mg; AW adult weight in $\mathrm{mg}$ and $\mathrm{WL}$ - wing length in $\mathrm{mm}$ ) of Aedes aegypti and Ae. albopictus reared with conspecifics (INTRA) or heterospecifics (INTER) using four different food types (FF - fish food; $\mathrm{P}$ - pulses; $\mathrm{R}+\mathrm{P}$ - rice + pulse and $\mathrm{R}-$ only rice) at a constant density of 20 individuals / $100 \mathrm{~mL}$. The data was taken on the basis of early (E) and late (L) emerging adults (based on the first and last 10 individuals). 


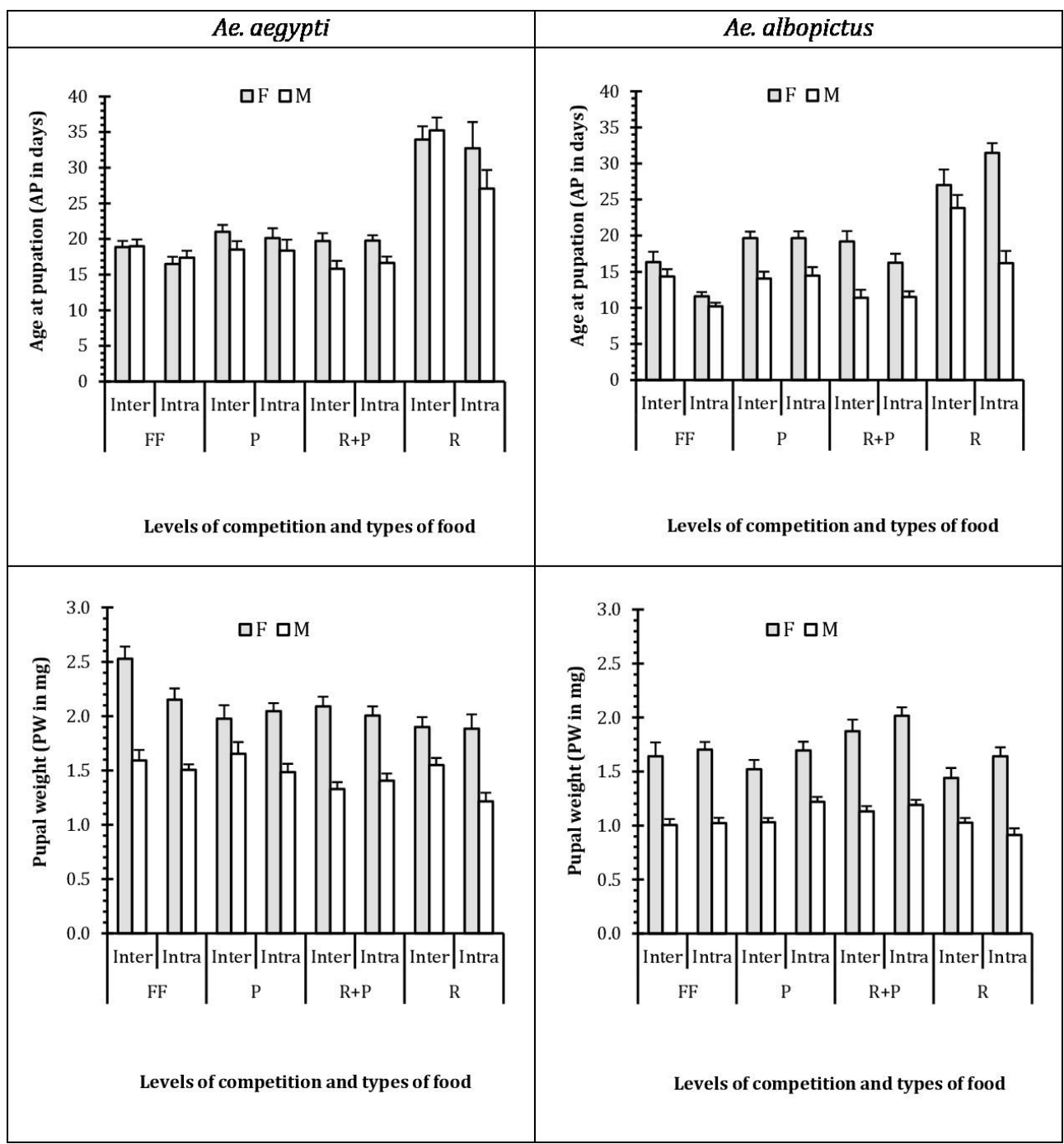

Fig. 2. Continued.

The results of univariate ANOVA show that for Ae. aegypti AP and $\mathrm{PW}$ varied significantly for all three explanatory variables, i.e. food type, competition level and sex, whereas the competition level had no significant effect on adult weight and food type had no significant effect on wing length in Ae. aegypti. Also, the interaction of the three explanatory variables had a significant effect on the response variables (Table 2). For Ae. albopictus AP varied significantly for all three explanatory variables as well as for all of their interactions. PW, AW and WL had a significant effect because of food variation and 


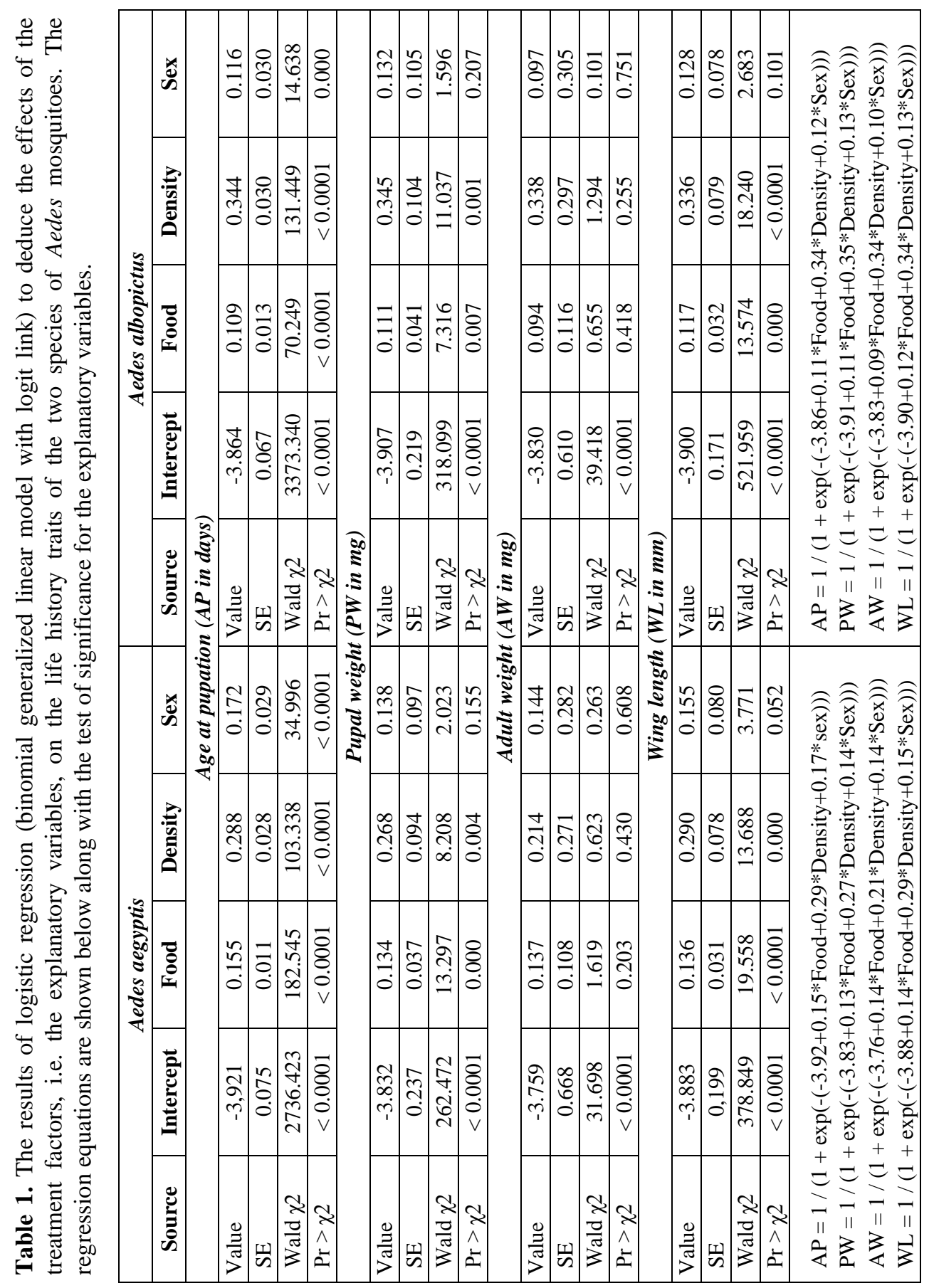


Table 2. The results of the univariate ANOVA using the food types, competition level and sex of the adults of both the species Aedes aegypti and Ae. albopictus as explanatory variables against the four life history traits $\mathrm{AP}, \mathrm{PW}, \mathrm{AW}$, and WL as response variables. The values in bold indicate significant differences at $\mathrm{P}<0.05$ level. MS - Mean Square.

\begin{tabular}{|c|c|c|c|c|c|c|}
\hline \multirow[t]{2}{*}{ Variable } & \multicolumn{3}{|c|}{ Aedes aegypti } & \multicolumn{3}{|c|}{ Aedes abopictus } \\
\hline & df & MS & $\mathbf{F}$ & df & MS & $\mathbf{F}$ \\
\hline \multicolumn{7}{|c|}{ Age of pupation } \\
\hline Food & 3 & 1723.416 & 56.770 & 3 & 1336.646 & 54.947 \\
\hline Comp & 1 & 155.226 & 5.113 & 1 & 302.833 & 12.449 \\
\hline Sex & 1 & 178.881 & 5.892 & 1 & 1844.569 & 75.826 \\
\hline Food $*$ Comp & 3 & 52.215 & 1.720 & 3 & 74.417 & 3.0591 \\
\hline Food $*$ Sex & 3 & 56.071 & 1.847 & 3 & 149.591 & 6.1494 \\
\hline Comp * Sex & 1 & 18.355 & 0.605 & 1 & 99.546 & 4.0921 \\
\hline Food $*$ Comp $*$ Sex & 3 & 32.830 & 1.081 & 3 & 123.293 & 5.0683 \\
\hline Error & 263 & 30.360 & & 284 & 24.326 & \\
\hline \multicolumn{7}{|c|}{ Pupal Weight (PW) } \\
\hline Food & 3 & 1.085 & 6.977 & 3 & 1.342 & 12.198 \\
\hline Comp & 1 & 0.713 & 4.582 & 1 & 0.290 & 2.639 \\
\hline Sex & 1 & 19.726 & 126.9 & 1 & 24.892 & 226.281 \\
\hline Food $*$ Comp & 3 & 0.205 & 1.321 & 3 & 0.101 & 0.921 \\
\hline Food $*$ Sex & 3 & 0.442 & 2.841 & 3 & 0.295 & 2.684 \\
\hline Comp * Sex & 1 & 0.009 & 0.056 & 1 & 0.162 & 1.476 \\
\hline Food $*$ Comp $*$ Sex & 3 & 0.329 & 2.116 & 3 & 0.065 & 0.593 \\
\hline Error & 263 & 0.156 & & 284 & 0.110 & \\
\hline \multicolumn{7}{|c|}{ Adult weight $(A W)$} \\
\hline Food & 3 & 0.013 & 3.528 & 3 & 0.009 & 2.868 \\
\hline Comp & 1 & 0.009 & 2.375 & 1 & 0.006 & 1.824 \\
\hline Sex & 1 & 0.339 & 88.57 & 1 & 0.608 & 187.601 \\
\hline Food $*$ Comp & 3 & 0.002 & 0.416 & 3 & 0.003 & 0.857 \\
\hline Food $*$ Sex & 3 & 0.033 & 8.517 & 3 & 0.003 & 1.025 \\
\hline Comp * Sex & 1 & 0.003 & 0.835 & 1 & 0.000 & 0.039 \\
\hline Food $*$ Comp $*$ Sex & 3 & 0.014 & 3.678 & 3 & 0.002 & 0.588 \\
\hline Error & 263 & 0.004 & & 284 & 0.003 & \\
\hline \multicolumn{7}{|c|}{ Wing length (WL) } \\
\hline Food & 3 & 0.081 & 1.436 & 3 & 1.342 & 12.198 \\
\hline Comp & 1 & 0.674 & 11.97 & 1 & 0.29 & 2.639 \\
\hline Sex & 1 & 9.351 & 166.2 & 1 & 24.892 & 226.281 \\
\hline Food $*$ Comp & 3 & 0.116 & 2.068 & 3 & 0.101 & 0.921 \\
\hline Food $*$ Sex & 3 & 0.117 & 2.084 & 3 & 0.295 & 2.684 \\
\hline Comp * Sex & 1 & 0.008 & 0.144 & 1 & 0.162 & 1.476 \\
\hline Food $*$ Comp $*$ Sex & 3 & 0.031 & 0.543 & 3 & 0.065 & 0.593 \\
\hline Error & 263 & 0.056 & & 284 & 0.11 & \\
\hline
\end{tabular}




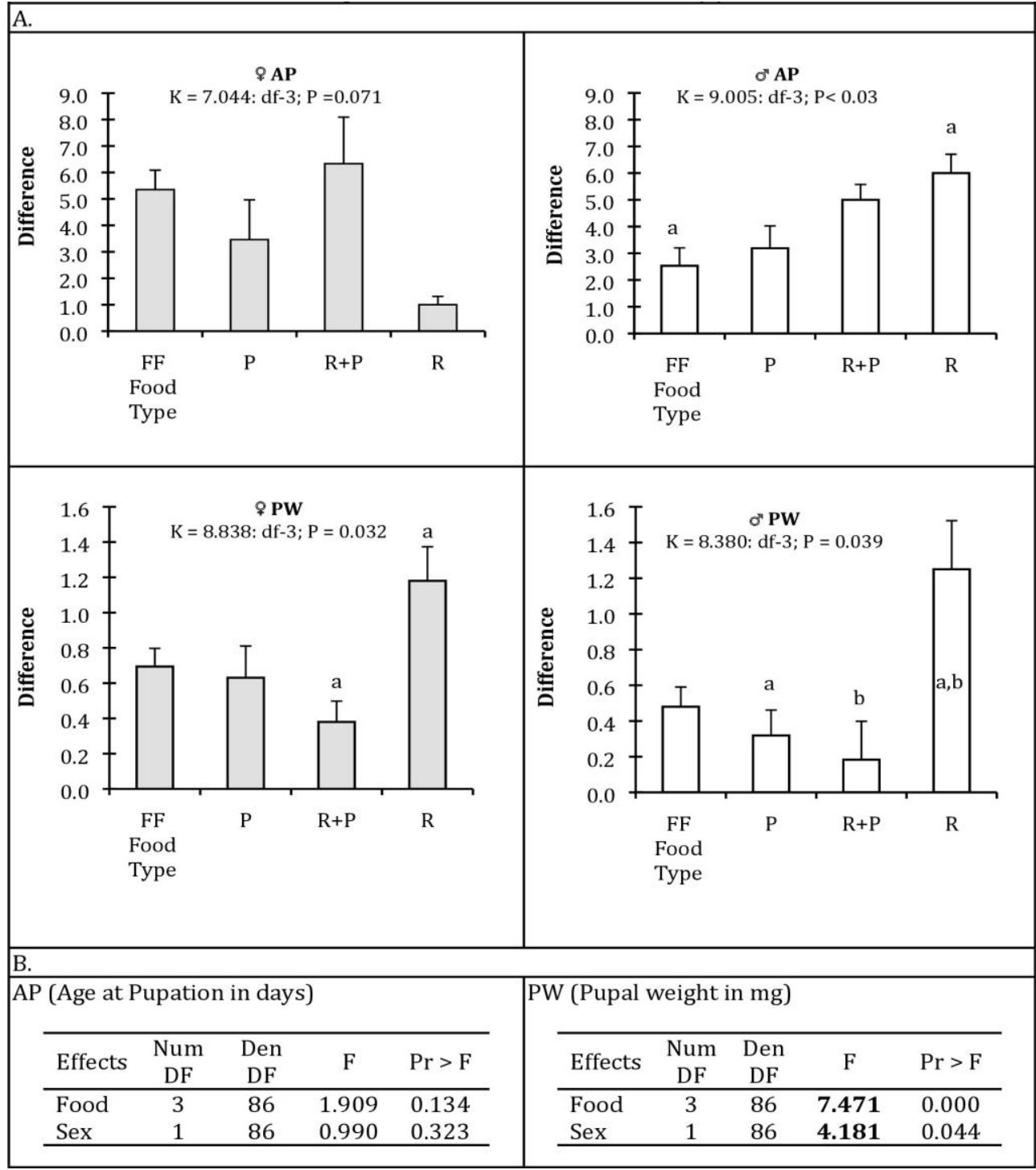

Fig. 3. Differences in life history traits between Aedes aegypti and Ae. albopictus reared together in equal abundance with four different food types (FF - fish food, $\mathrm{R}$ - boiled rice, $\mathrm{P}-$ boiled pulses, $\mathrm{R}+\mathrm{P}$ - boiled rice and pulse) provided ad libitum. The data were compared using the Kruskal-Wallis test with multiple comparisons following the SteelDwass-Critchlow method with Bonferroni correction (A). The results of GLM Mixed model ANOVA using food types and sex of the adults of both Ae. aegypti and Ae. albopictus as explanatory variables and the differences in the life history traits (AP, PW, AW, WL) of the two species as response variables. The values in bold indicate significant differences at the $\mathrm{P}<0.05$ level. The values in bold indicate significant differences at the $\mathrm{P}<$ 0.05 level (B). 


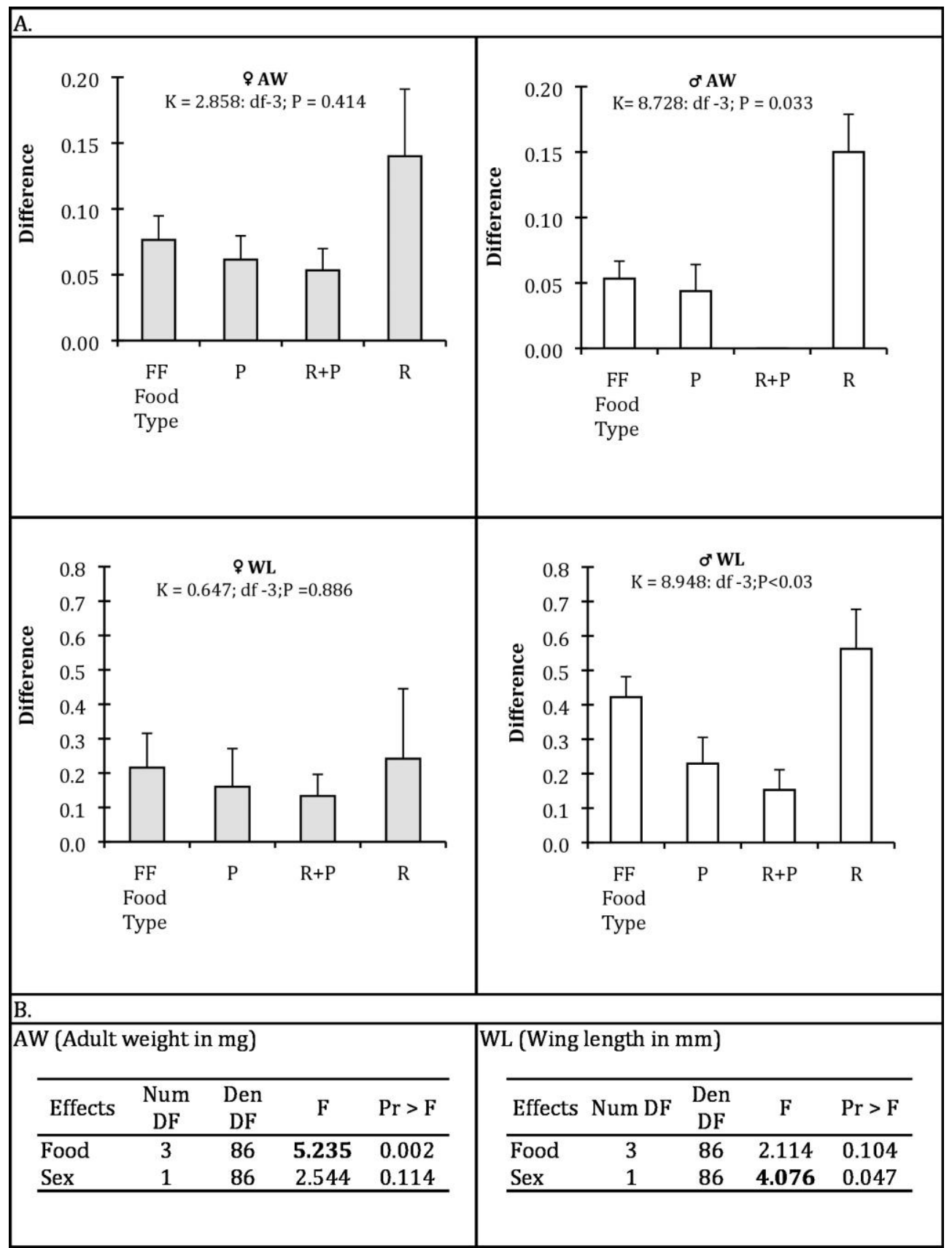

Fig. 3. Continued. 
sex (Table 2). The life history traits of Ae. aegypti and Ae. albopictus are compared in Fig. 3. In almost all instances, the values are in favour of Ae. aegypti, illustrating the fact that Ae. albopictus reached the pupal stage early, with lower pupal weight, adult weight and wing length in both sexes. For the males, the differences in all the life history traits were significant, but for females only the pupal weight was significantly different when the food types were considered as a source of the variations. The result thus indicates that food quality induced differential effects on the two competing mosquitoes Ae. aegypti and Ae. albopictus, resulting in early emergence but smaller mosquitoes in the latter.

\section{DISCUSSION}

Competitive interactions in the larval stages of Aedes mosquitoes influence the morphological and physiological characteristics of the adults (BRIEGEL 1990, GRIMSTAD \& WALKER 1991, SUMANOCHITRAPON et al. 1998, BRIEGEL \& TiMMERMANN 2001). Since body size and wing length are linked with the longevity and reproductive success of Aedes, competitive interactions are significant in shaping the population. Both interspecific and intraspecific competition influence the life history traits of Ae. aegypti and Ae. albopictus to a considerable extent (AGNEW et al. 2002, JULIANO 2009, 2010) and can thus be considered a vital factor for disease transmission potential (ALTO et al. 2008a, 2008b). The disease transmission potential of dengue vectors is linked with the fitness of the mosquitoes (JULIANO et al. 2014), reflected through body size and various life history traits that are influenced by larval development and the resources acquired during the larval stages. Resource-based competition in Ae. aegypti and Ae. albopictus arises out of the similarities in their biology and ecology. Both species of Aedes mosquitoes breed in artificial containers of different materials and origins (MEDRONHO et al. 2009, BURKE et al. 2010), which are, in many instances linked with household disposables (BANERJEE et al. 2013b, 2015). The development of the larval stages is greatly dependent on the resource content in these containers and can act as a limiting factor during overcrowded conditions. Similar conditions are observed in Aedes mosquitoes in other natural larval habitats (BRADSHAW \& Holzapfel 1992, Clements 1992, Renshaw et al. 1994), which affects larval development and population growth (BROADIE \& BRADSHAW 1991, RENSHAW et al. 1994, MUNSTERMANN \& CONN 1997, LORD 1998). Such competitive interactions and resultant effects on the prospective viral role have been established by different studies (ALTO et al. 2008a, 2008b, PADMANABHA et al. 2011, MUTURI et al. 2012). Exploration of resourcebased competition and its effect on the life history traits of Ae. aegypti and Ae. albopictus is thus imperative for a better understanding of their biology. 
In the present study, an assessment was done to correlate resource-dependent competitive interactions and life history traits of Ae. aegypti and Ae. albopictus. In view of the results obtained it appears that both species are affected by interspecific rather than intraspecific competition with respect to all food levels and both sexes. The pattern of competitive interactions appears to resemble the conditions where the food supplied to the competing larvae was supplemented with additional resources, such as insect carcasses (DAUGHERTY et al. 2000). Inter- and intraspecific competition between Ochlerolatus caspius and Culiseta longiareolata also showed a similar kind of response when the initial density was varied (TSURIM et al. 2013). In separate studies, the effects of food on this competition resulted in differential responses by the two Aedes mosquitoes (AGNEW et al. 2002, YEE et al. 2004). Several studies have been conducted on competitive interactions between Ae. albopictus and Ae. aegypti with variations in the food substrates (DAUGHERTY et al. 2000, Yee et al. 2007, Murrell \& Juliano 2008, BArA et al. 2014, Couret et al. 2014). The outcome of the competitive interactions was in favour of Ae. aegypti (MOORE \& FISHER 1969), or of Ae. albopictus, and in a few instances, both species were equal as competitors (BLACK et al. 1989, Ho et al. 1989, DAUGHERTY et al. 2000, LOUNIBOS et al. 2002, Alto et al. 2005, 2008a, MuRRell \& JULIANO 2008). On a comparative scale, the outcome of competitive interactions is context-dependent, with the presence of one food type favouring one of the two species (DAUGHERTY et al. 2000, MURRELl \& JULIANO 2008). However, variation of the amount of food was used as a factor influencing the outcome of the competition in majority of instances (JULIANO 2009). In the present study, food quality was a factor that influenced the outcome of competition as measured by the life history traits. Although the assessments were conducted using a fixed rearing density of the developing larvae, the results suggest that food type differentially affects the life history traits under conditions of intra- and interspecific competition. For both the Aedes species, the outcome of the competitive impact may have consequences in the population build-up and elimination of one species at the cost of the other. However, adult survival and reproductive success is required to substantiate such a proposition, which will have to be assessed in further studies. Nonetheless, the present study has shown that food quality can be a source eliciting differential responses by the mosquitoes under conspecific and heterospecific conditions.

In the context of resource-based interspecific competition, it is apparent from the results that Ae. albopictus outcompeted Ae. aegypti in terms of larval development time (AP), but pupal weight (PW), adult weight (AW) and wing length (WL) were higher in the latter. As a consequence of the heterospecific interactions between the two species, it seems that $A e$. albopictus employs a superior strategy in the competition with Ae. aegypti. In situations where the two species coexist, Ae. albopictus may emerge as the dominant species with a higher relative abundance but smaller body size, whereas in Ae. aegypti body size may be 
larger but the developmental time longer. Body size has an immense effect on vector competence, as demonstrated by studies of Ae. aegypti (Juliano et al. 2014) and Aedes triseriatus (PAULSON \& HAWLEY 1991). Energy reserves in adult Aedes depend on resource acquisition in the larval stages, which may be affected by nutritional deprivation during larval development. Females with larger body sizes are said to have greater energy reserves than smaller ones. After eclosion to the adult stage, females with greater energy reserves can utilize them for survival and flight performance; moreover, a substantial proportion can be used to initiate oogenesis if the energy reserves have a threshold lipid content (BRIEGEL \& HöRLER 1993). But smaller females, having lower energy reserves, require blood meals for their survival at a very early part of the adult stage; as a result, multiple feeding in the early days of the adult stage enhance their potential for disease transmission (TAKKEN et al. 1998). The consequence of interspecific competition between the two species may therefore have different effects in the adults and thus roles in disease transmission. It appears that the strategies of the two species are different under conditions of interspecific competition. For Ae. albopictus, the early development but smaller size may facilitate the faster completion of the life cycle and thus chances to dominate, whereas Ae. aegypti may develop late but attain a comparatively larger size, thereby posing a greater risk of disease transmission owing to the ability to host a higher number of pathogens. Although transmission is inevitable in both cases, the role of the species may vary depending on the competitive interactions they are involved in.

\section{ACKNOWLEDGEMENTS}

We are grateful to the two reviewers for their comments that enabled us to improve the manuscript to its present form. We also thank Dr Paweł BUCZYŃSKI, Editor, for his kind encouragement and support in revising the manuscript to its present form. The authors gratefully acknowledge the Head of the Department of Zoology, University of Calcutta, Kolkata, India, for the facilities provided, including infrastructure under DST-FIST, Government of India. The first author SB acknowledges the financial support of DST, GoI, under DST-INSPIRE fellowship in pursuing this research work (sanction number: DST/INSPIRE Fellowship/2013/645, dated 17.12.13).

\section{REFERENCES}

AdDinSOFt SARL 2010. XLSTAT software, Version 10.0. Paris, France. 
Agnew P., Haussy C., Michalakis Y. 2000. Effects of density and larval competition on selected life history traits of Culex pipiens quinquefasciatus (Diptera: Culicidae). Journal of Medical Entomology 37(5): 732-755.

Agnew P., Hide M., Sidobre C., Michalakis Y. 2002. A minimalist approach to the effects of density dependent competition on insect life history traits. Ecological Entomology 27(4): 396-402.

Alto B.W., BetTinaRdi D.J., ORTIZ S. 2015. Interspecific larval competition differentially impacts adult survival in dengue vectors. Journal of Medical Entomology 52(2): 163-170

Alto B.W., Lounibos L.P., Mores C.N., Reiskind M.H. 2008a. Larval competition alters susceptibility of adult Aedes mosquitoes to dengue infection. Proceedings of the Royal Society B 275(1633): 463-471.

Alto B.W., ReISKIND M.H., Lounibos L.P. 2008b. Size alters susceptibility of vectors to dengue virus infection and dissemination. The American Journal of Tropical Medicine and Hygiene 79(5): 688-695.

Ambruster P., Hutchinson R.A. 2002. Pupal mass and wing length as indicators of fecundity in Aedes albopictus and Aedes geniculatus (Diptera: Culicidae). Journal of Medical Entomology 39(4): 699-704.

Arrivillaga J., Barrera R. 2004. Food as a limiting factor for Aedes aegypti in water-storage containers. Journal of Vector Ecology 29(1): 11-20.

BanerJee S., Aditya G., Saha G.K. 2013a. Pupal productivity of dengue vectors in Kolkata, India: implications for vector management. Indian Journal of Medical Research 137(3): 549-559.

BANERJEE S., Aditya G., SAHA G.K. 2013b. Household disposables as breeding habitats of dengue vectors: linking wastes and public health. Waste Management 33(1): 233-239.

BANeRJeE S., Aditya G., SAHA G.K. 2015a. Household wastes as larval habitats of dengue vectors: comparison between urban and rural areas of Kolkata, India. PLoS ONE 10(10): e0138082.

BanerJee S., Mohan S., Saha N., Mohanty S.P., Saha G.K., Aditya G. 2015b. Pupal productivity $\&$ nutrient reserves of Aedes mosquitoes breeding in sewage drains \& other habitats of Kolkata, India: implications for habitat expansion \& vector management. Indian Journal of Medical Research 142(Supl. 1): 87-94.

Bara J., Rapti Z., CÁCeres C.E., Muturi E.J. 2014. Effect of larval competition on extrinsic incubation period and vectorial capacity of Aedes albopictus for dengue virus. PLoS ONE 10(5): $\mathrm{e} 0126703$

BARRERA R. 1996. Competition and resistance to starvation in larvae of container-inhabiting Aedes mosquitoes. Ecological Entomology 21(2): 117-127.

Bédhomme S., Agnew P., Sidobre C., Michalakis Y. 2005. Pollution by conspecifics as a component of intraspecific competition among Aedes aegypti larvae. Ecological Entomology 30(1): $1-7$.

Black W.C. IV, RAi K.S., TurCo B.J., Arroyo D.C. 1989. Laboratory study of competition between United States strains of Aedes albopictus and Aedes aegypti (Diptera: Culicidae). Journal of Medical Entomology 26(4): 260-271. 
Bradshaw W.E., Holzapfel C.M. 1992. Reproductive consequences of density-dependent size variations in the pitcher plant mosquito, Wyeomyia smithii (Diptera: Culicidae). Annals of Entomological Society of America 85: 274-281.

Braks M.A.H., Honório N.A., Lounibos L.P., Lourenço-De-Oliveira R., Juliano S.A. 2004. Interspecific competition between two invasive species of container mosquitoes, Aedes aegypti and Aedes albopictus (Diptera: Culicidae), in Brazil. Annals of Entomological Society of America 97(1): 130-139.

BRIEGEL H. 1990. Metabolic relationship between female body size, reserves, and fecundity in Aedes aegypti. Journal of Insect Physiology 36(3): 165-172.

BRIEGEl H., HöRLER E. 1993. Multiple blood meals as a reproductive strategy in Anopheles (Diptera: Culicidae). Journal of Medical Entomology 30(6): 975-985.

Briegel H., Timmermann S.E. 2001. Aedes albopictus (Diptera: Culicidae): physiological aspects of development and reproduction. Journal of Medical Entomology 38(4): 566-571.

BROADIE K.S., Bradshaw W.E. 1991. Mechanisms of interference competition in the Western treehole mosquito, Aedes sierrensis. Ecological Entomology 16(2): 145-154.

Burke R., Barrera R., Lewis M., Kluchinsky T., Claborn D. 2010. Septic tanks as larval habitats for the mosquitoes Aedes aegypti and Culex quinquefasciatus in Playa-Playita, Puerto Rico. Medical and Veterinary Entomology 24(2): 117-123.

CLEMENTS A.N. 1992. The biology of mosquitoes: development, nutrition and reproduction. Chapman \& Hall, London.

Couret J., Dotson E., Benedict M.Q. 2014. Temperature, larval diet, and density effects on development rate and survival of Aedes aegypti (Diptera: Culicidae). PLoS ONE 9(2): e87468.

Daugherty M.P., Alto B.W., Juliano S.A. 2000. Invertebrate carcasses as a resource for competing Aedes albopictus and Aedes aegypti (Diptera: Culicidae). Journal of Medical Entomology 37(3): 364-372.

Ewing D.A., Cobbold C.A., Purse B.V., Nunn M.A., White S.M. 2016. Modelling the effect of temperature on the seasonal population dynamics of temperate mosquitoes. Journal of Theoretical Biology 400(7): 65-79.

Gavotte L., Mercer D.R., Vandyke R., Mains J.W., Dobson S.L. 2009. Wolbachia infection and resource competition effects on immature Aedes albopictus (Diptera: Culicidae). Journal of Medical Entomology 46(3): 451-459.

Gilles J.R.L., LeES R.S., Soliban S.M., Benedict M.Q. 2011. Density-dependent effects in experimental larval populations of Anopheles arabiensis (Diptera: Culicidae) can be negative, neutral, or overcompensatory depending on density and diet levels. Journal of Medical Entomology 48(2): 296-304.

Grimstad P.R., Walker E.D. 1991. Aedes triseriatus (Diptera: Culicidae) and La Crosse virus. IV. Nutritional deprivation of larvae affects the adult barriers to infection and transmission. Journal of Medical Entomology 28(3): 378-386.

Ho B.C., Ewert A., CHEw L. 1989. Interspecific competition among Aedes aegypti, Ae. albopictus, and Ae. triseriatus (Diptera: Culicidae): larval development in mixed cultures. Journal of Medical Entomology 26(6): 615-23. 
JuLIANO S.A. 1998. Species introduction and replacement among mosquitoes: interspecific resource competition or apparent competition? Ecology 79(1): 255-268.

JuLiano S.A. 2009. Species interactions among larval mosquitoes: context dependence across habitat gradients. Annual Review of Entomology 54: 37-56.

JuLiAno S.A. 2010. Coexistence, exclusion, or neutrality? A meta-analysis of competition between Aedes albopictus and resident mosquitoes. Israel Journal of Ecology and Evolution 56(3-4): 1-26.

Juliano S.A., Lounibos L.P., O'Meara G.F. 2004. A field test for competitive effects of Aedes albopictus on Aedes aegypti in South Florida: differences between sites of coexistence and exclusion? Oecologia 139(4): 583-593.

Juliano S.A., O’Meara G.F., Morrill J.R., Cutwa M.M. 2002. Desiccation and thermal tolerance of eggs and the coexistence of competing mosquitoes. Oecologia 130(3) 458-469.

Juliano S.A., Ribeiro G.S., Maciel-De-Freitas R., Castro M.G., Codeço C., Lourenço-DeOliveira R., Lounibos LP. 2014. She's a femme fatale: low-density larval development produces good disease vectors. Memórias Do Instituto Oswaldo Cruz Rio de Janeiro 109(8): 1070-1077.

Kamgang B., Happi J.Y., Boisier P., Nuiokou F., Hervé J.P., Simard F., Paupy C. 2010. Geographic and ecological distribution of dengue and chikungunya virus vectors, Aedes aegypti and Aedes albopictus, in urban environments of Cameroon (Central Africa). Medical and Veterinary Entomology 24(2): 132-141.

KIRBY M.J., LindSAY S.W. 2009. Effect of temperature and inter-specific competition on the development and survival of Anopheles gambiae sensu stricto and An. arabiensis larvae. Acta Tropica 109(2): 118-123.

Legros M., Lloyd A.L., Huang Y., Gould F. 2009. Density-dependent intraspecific competition in the larval stage of Aedes aegypti (Diptera: Culicidae): revisiting the current paradigm. Journal of Medical Entomology 46(3): 409-419.

LORD C.C. 1998. Density dependence in larvae of Aedes albopictus (Diptera: Culicidae). Journal of Medical Entomology 35(5): 825-829.

Lounibos L.P., SuÁrez S., Menéndez Z., Nishimura N., Escher R.L., O’Connell S.M., Rey J.R. 2002. Does temperature affect the outcome of larval competition between Aedes aegypti and Aedes albopictus? Journal of Vector Ecology 27(1): 86-95.

Medronho R.A., Macrini L., Novellino D.M., Lagrotta M.T.F., CÂmara V.M., Pedreira C.E. 2009. Aedes aegypti immature forms distribution according to type of breeding site. The American Journal of Tropical Medicine and Hygiene 80(3): 401-404.

MerRitT R.W., DAdD R.H., WALKER E.D. 1992. Feeding behavior, natural food, and nutritional relationships of larval mosquitoes. Annual Review of Entomology 37: 349-376.

Mohan S., BanerJee S., Mohanty S.P., Saha G.K., Aditya G. 2014. Assessment of pupal productivity of Aedes and co-occurring mosquitoes in Kolkata, India. Southeast Asian Journal of Tropical Medicine and Public Health 45(6): 1279-1291.

Moore C.G., Fisher B.R. 1969. Competition in mosquitoes. Density and species ratio effects on growth, mortality, fecundity, and production of growth retardant. Annals of the Entomological Society of America 62(6): 1325-1331. 
Munstermann L.E., Conn J.E. 1997. Systematics of mosquito disease vectors (Diptera, Culicidae) Impact of molecular biology and cladistic analysis. Annual Review of Entomology 42: 351-369.

Murrell E.G., Juliano S.A. 2008. Detritus type alters the outcome of interspecific competition between Aedes aegypti and Aedes albopictus (Diptera: Culicidae). Journal of Medical Entomology 45(3): 375-383.

Muturi E.J., Blackshear M. Jr., Montgomery A. 2012. Temperature and density-dependent effects of larval environment on Aedes aegypti competence for an alphavirus. Journal of Vector Ecology 37(1): 154-161.

O’Meara G.F., Evans L.F., GetTMan A.D., Cuda J.P. 1995. Spread of Aedes albopictus and decline of Aedes aegypti (Diptera: Culicidae) in Florida. Journal of Medical Entomology 32(4): 554-562.

Padmanabha H., BolKer B., Lord C.C., Rubio C., Lounibos L.P. 2011. Food availability alters the effects of larval temperature on Aedes aegypti growth. Journal of Medical Entomology 48(5): 974-984.

PAULSON S.L., HAWley W.A.1991. Effect of body size on the vector competence of field and laboratory population of Aedes triseriatus for La Crosse virus. Journal of American Mosquito Control Association 7(2): 170-175.

REISKIND M.H., LOUNIBOS L.P. 2009. Effects of intraspecific larval competition on adult longevity in the mosquitoes Aedes aegypti and Aedes albopictus. Medical and Veterinary Entomology 23(1): $62-68$.

Renshaw M., Service M.W., Birley M.H. 1994. Size variation and reproductive success in the mosquito Aedes cantans. Medical and Veterinary Entomology 8(2): 179-186.

Rey J.R., Nishimura N., Wagner B., Braks M.A.H., O'Connell S.M., Lounibos L.P. 2006. Habitat segregation of mosquito arbovirus vectors in south Florida. Journal of Medical Entomology 43(6):1134-1141.

Sumanochitrapon W., Strickman D., Sithiprasasna R., KitTayapong P., Innis B.L. 1998. Effect of size and geographic origin of Aedes aegypti on oral infection with dengue-2 virus. American Journal of Tropical Medicine and Hygiene 58(3): 283-286.

Takken W., Klowden M.J., Chambers G.M. 1998. Effect of body size on host seeking and blood meal utilization in Anopheles gambiae sensu stricto (Diptera: Culicidae) the disadvantage of being small. Journal of Medical Entomology 35(5): 639-445.

Tsurim I., Silberbush A., Ovadia O., Blaustein L., Margalith Y. 2013. Inter- and intra-specific density-dependent effects on life history and development strategies of larval mosquitoes. PLoS ONE 8(3): e57875.

VeZZAni D., Schweigmann N., 2002. Suitability of containers from different sources as breeding sites of Aedes aegypti (L.) in a cemetery of Buenos Aires city, Argentina. Memórias do Instituto Oswaldo Cruz 97(6): 789-792.

WALKer E.D., O’Meara G.F., Morgan W.T. 1996. Bacterial abundance in larval habitats of Aedes albopictus (Diptera: Culicidae) in a Florida cemetery. Journal of Vector Ecology 21(2): 173-177.

Westbrook C.J., Reiskind M.H., Pesko K.N., GreEne K.E., Lounibos L.P. 2010. Larval environmental temperature and the susceptibility of Aedes albopictus Skuse (Diptera: Culicidae) to Chikungunya virus. Vector Borne and Zoonotic Disease 10(3): 241-247. 
Yee D., Kesavaraju B., Juliano S.A. 2004. Interspecific differences in feeding behavior and survival under food-limited conditions for larval Aedes albopictus and Aedes aegypti (Diptera: Culicidae). Annals of the Entomological Society America 97(4): 720-728.

Yee D.A., Kaufman M.G., Juliano S.A. 2007. The significance of ratios of detritus types and microorganism productivity to competitive interactions between aquatic insect detritivores. Journal of Animal Ecology 76(6): 1105-1115.

ZAR J.H. 1999. Biostatistical analysis (fourth edition). Prentice Hall, Englewood Cliffs (NJ).

Received: 3 October 2016

Accepted: 20 December 2016 